\title{
Lexical decomposition of English spatial particles and their subsumption in motion constructions ${ }^{1}$
}

\author{
Ignasi Navarro i Ferrando \\ navarroi@uji.es \\ Universitat Jaume I, Spain
}

\begin{abstract}
In this paper, we firstly present a tentative formalization of a Lexical Template (LT) and a meta-language for spatial particle semantics within the framework of the Lexical Constructional Model (LCM). The semantic module consists of a set of Lexical Functions, which operate on a semantic primitive in order to produce a hyponym by elaborating topological, dynamic and functional information. The syntactic module expresses situations (positions or states) plus the argument structure. Secondly, we illustrate and discuss several LTs with the purpose of exploring spatial particle subsumption constraints with constructions such as caused motion and intransitive motion, as well as the types of verbal Aktionsart that might fuse with them. The COCA is used as a data source. We conclude that spatial particles contribute meaning to the extent that they partially determine the type of Aktionsart of the verb licensed by the motion construction.
\end{abstract}

Keywords: spatial particle, lexical template, motion construction, subsumption, Aktionsart

\section{INTRODUCTION}

The first aim of this paper is to explore the lexical decomposition of spatial particles so as to introduce their lexical templates within the framework of the Lexical Constructional Model (henceforth LCM). Secondly, we discuss the semantic contribution of spatial particles to motion constructions, more precisely, to the Intransitive Motion Construction and the Caused Motion Construction. The current approach in Construction Grammar (Goldberg 1995: 164ff) avoids going into details about spatial particle meanings and holds that finite verbs fuse into constructions, so that whenever their semantic specifications do not match, the construction overrides the semantic value of the verb, thereby subsumed on the basis of the coercion principle. Nothing is said about other lexical units participating in the construction, like spatial particles. Particle semantics is ignored, since the path is considered part of the constructional meaning: "the location encoded by the locative phrase is interpreted to be the endpoint of a path to that location” (Goldberg 1995: 159). Conversely, we claim that 
at least part of the semantic value attributed to the construction is contributed by spatial particles.

To provide evidence of our claim, that is, to show the meaning contributed by the particle and how that meaning matches the construction, we have carried out lexical decomposition in the form of lexical and constructional templates within the framework of the LCM.

The LCM (Butler 2009, Mairal and Ruiz de Mendoza 2008, 2009, Ruiz de Mendoza and Mairal 2007a, 2007b, 2008) proposes a semantic-syntactic system of representation of both lexical units and constructions.

The use of a predicate, i.e., a lexical unit, in a particular construction is defined by a cognitive operation called subsumption (Peña 2009), which assumes both internal (semantic-syntactic) and external (pragmatic and discursive) constraints. The descriptive tools used for the formalization of subsumption processes are called Lexical Templates (henceforth LTs) and Constructional Templates (henceforth CTs), which share a common meta-language. LTs are semantic representations of the syntactically relevant content in the meaning of a lexical unit plus pragmatic and semantic information relevant to that meaning. CTs are similar formalizations of constructional meaning. Therefore, semantic decomposition of lexical predicates becomes necessary so as to determine the elements required in their semantic representation. In its attempt to provide a more adequate explanation for the syntactic-semantic interface, the LCM has a twofold goal:

1) Firstly, to identify the aspects of meaning which determine alternate usage of lexical units belonging to the same class, as well as to investigate why certain classes of lexical units participate in a given set of constructions while others do not.

2) Secondly, to provide a set of rules that regulates the fusion process (subsumption) considering semantic motivation at its basis. Contrary to most theories of lexical representation, the LCM claims that "a lexical rule should not only capture those idiosyncratic regularities that hold in the lexicon, but it should also explain the linguistic motivation that exists behind the generation of a given syntactic construction” (Mairal 2004: 11). 
Within this framework, our goal is to unravel the semantic role of particles both in the Intransitive Motion Construction and, especially, in the Caused Motion Construction. We provide evidence that shows the kind of meaning contributed by the particle and how that meaning matches the construction.

\section{THE STRUCTURE OF LEXICAL AND CONSTRUCTIONAL TEMPLATES}

LTs are low-level semantically-enriched representations of the syntactically relevant content of a predicate meaning, plus pragmatic and semantic information relevant to that meaning. The structure of these formulaic representations emerges from the formalism developed in Role and Reference Grammar (RRG) for Logical Structures (Van Valin 2005). In LCM, however, these representations are enhanced by means of lexical functions and lexical domain decomposition (Mairal and Faber 2005, 2007). In other words, what the templates provide is a semantic specification of a Logical Structure. The goal of that construct in the LCM framework is to stretch the chain of semantic decomposition as much as possible, as well as to develop a universal metalanguage that supplies typologically valid representations. With that purpose, semantic decomposition in LCM observes the following components:

a) Lexical Inheritance Hierarchy: LTs are interrelated through domain-subdomain hierarchies (Faber and Mairal 1999).

b) A set of semantic primitives of the BE, HAPPEN, BECOME, HAVE, etc. type (Wierzbička 1996).

c) A set of Lexical Functions of the $f(x)=y$ type (Mel'čuk et al. 1995). Lexical Functions (e.g. Magn, Culm, Manner, Cont, CAuse, Instr, etc.) can account for lexical domain-specific relationships and elements of world knowledge that relate in a specific way to the predicate defined by the LT.

d) Aktionsart distinctions that result in a classification of event types which distinguishes among states, activities, achievements, semelfactives, accomplishments, active accomplishments, and causative accomplishments (Vendler 1967, Van Valin 2005). These distinctions are based on event parameters such as $+/$ - static, $+/$ - dynamic, +/- telic, and +/- punctual). States (e.g. know) and activities (e.g. run) are considered 
primitive kinds of durative, non-telic events, static or dynamic, respectively. Semelfactives (e.g. sneeze) are punctual, non-telic events, i.e., events without a change of state. Achievements (e.g. shatter) and accomplishments (e.g. melt, get) imply a change of state (BECOME).

e) Argument Structure: predicate arguments (x, y, etc.).

In accordance with the parameters set out above, enhanced formalism, as outlined by Mairal and Faber (2005, 2007), includes a semantic module (Lexical Inheritance and Lexical Functions) plus a syntactic module (Aktionsart and Argument Structure).

Semantic primitives and Lexical Functions characterize the semantic component of the language lexicon. The inventory of primitives is systematic, finite and internally consistent. That inventory defines a set of lexical domains that determine the architecture of the lexical system. Thus, each lexical domain is defined by a superordinate term called a nuclear term (e.g. the domain of verbs of existence is defined by the superordinate be or happen, the domain of change verbs is defined by become, the domain of possession verbs is defined by have, and so on:

$\begin{array}{ll}\text { DOMAIN } & \text { NUCLEAR TERM } \\ \text { Existence } & \text { be, happen } \\ \text { Change } & \text { become } \\ \text { Possession } & \text { have } \\ \text { Speech } & \text { say } \\ \text { Emotion } & \text { feel } \\ \text { Action } & \text { do, make } \\ \text { Cognition } & \text { know, think } \\ \text { Movement } & \text { move, (go/come) } \\ \text { Physical perception } & \text { see, hear, taste, smell, touch } \\ \text { Manipulation } & \text { use }\end{array}$

Each superordinate term can be used for the formulation of more specific lexical items or hyponyms, which in turn inherit information from the superordinate unit. Thus, see may be used as a prime in the lexical templates of verbs like look, watch, observe, glimpse, etc. This proposal of a set of primitive terms coincides to a great extent with Wierzbička's 
Natural Semantic Metalanguage (NSM), which has been shown to be valid for over a hundred languages (Wierzbička 1996).

The semantic component of the LCM lexicon also includes a set of operators based on the notion of Lexical Function as propounded by Explanatory and Combinatorial Lexicology (Mel'čuk et al. 1995). A large set of such semantic operators have also been shown to have universal status. In Mel'čuk's theory, Lexical Functions operate syntagmatically, so that a lexical unit may combine with certain collocates when a function is applied to it. For example, the function "intensification”, expressed as $<$ MAGN $>$, can be applied to different lexical units, for instance to the unit smoker. As a result, the expression 'heavy smoker' emerges in the language, with the consequence that the unit "heavy", as collocate of “smoker”, expresses that particular lexical function.

In LCM, the notion of Lexical Function is applied paradigmatically in the lexicon, with the purpose of describing the semantic relationship between different lexical units in a lexical hierarchy. Thus, a hyponym is described as a hyperonym incorporating one or more Lexical Functions into the semantic module of its LT. Thus, in $f(x)=y, f$ represents the function, $x$ represents the hyperonym, and $y$ stands for the hyponym. The meaning associated with a Lexical Function is abstract and general, and can produce a relatively high number of values. In LCM, therefore, Lexical Functions are essentially paradigmatic - instead of syntagmatic - operators, and capture those pragmatic and semantic parameters that are idiosyncratic to the meaning of a word, which allows for distinctions of different words within the same lexical hierarchy. The following formula shows the schematic form of an LT:

predicate:

[semantic module $<$ lexical functions $>$ ] [aktionsart module $<$ semantic primes $>$ (thematic frame)]

To illustrate the notion of LT, let us look, by way of example, at the following hierarchy of visual perception verbs:

Superordinate term: see $(\mathrm{x}, \mathrm{y})$

Hyponymy hierarchy:

distinguish $>\left[\mathrm{ID}_{12}\right.$ and $\left.\mathrm{EFF}\right]\left[\right.$ see' $\left.^{\prime}(\mathrm{x}, \mathrm{y})\right]$

look $\quad$ [INTENT, CONT] see' $(\mathrm{x}, \mathrm{y})$ 


$$
\begin{aligned}
& \text { watch }>\quad\left[\text { MAGN and INTENT, CONT }^{\text {lng }}\right] \text { see }^{\prime}(\mathrm{x}, \mathrm{y}) \\
& \text { observe }>\quad \text { PURP and [MAGN and INTENT, CONT }{ }^{\text {lng }} \text { ] see' }(\mathrm{x}, \mathrm{y})
\end{aligned}
$$

In these LTs, see, distinguish, look, watch and observe stand for the predicates under description; ID, EFF, INTENT, CONT, MAGN, and PURP stand for the Lexical Functions identification, effort, intentionality, continuity, intensification and purpose; the subscript figures 12 stand for the transitive character of the identification function, which affects the two arguments; see' stands for a visual perception stative primitive; and, finally, (x, y) stands for an argument structure including two arguments.

We have illustrated the structure of LTs and the meta-language employed in their semantic decomposition. The same kind of configuration and meta-language is used in the semantic description of constructions. CTs are present in different forms (e.g. argumental and idiomatic) at all levels of linguistic description (propositional, inferential, pragmatic and discursive). Thus, a CT is viewed as a high-level or abstract semantic representation of syntactically relevant meaning elements that are abstracted away from multiple lower-level representations, as in:

Intransitive motion: [do’ (x) [BECOME be-LOC’ (x, z)]

(1) Paul walked into the room

Caused motion: [do’ (x,y)] CAUSE [BECOME be-LOC’ (y, z)] (from PérezHernández and Peña-Cervel 2009)

(2) Paul put the napkin in the drawer

The CTs above encode motion constructions, so that, firstly, an entity (x) does an action (do). Moreover, in the intransitive motion construction, that entity (x) ends at location (z) by the effect of the action (do). The expression BECOME be-LOC' encodes the meaning 'change of location'. In the case of the caused motion construction, the action performed by (x) on another entity (y) causes that entity (y) to change its location.

\section{LTS OF SPATIAL PARTICLES}

In the following subsections, we introduce a characterization of the components in an LT of a spatial particle. 


\section{III.1. Argument structure}

In Cognitive Grammar (Langacker 1987), spatial particles are considered lexical units of a relational nature, as are verbs:

... a relationship is conceptually dependent on its participants. For example, we cannot conceptualize a spatial relation (like on, under, or near) without to some extent (if only schematically) invoking the entities that participate in it. As the term suggests, apprehending a relationship resides in conceiving entities in relation to one another. Thus it does not exist independently of those entities. (Langacker 2008: 200)

English spatial particles are relational expressions, so that the speaker's conceptualization profiles interconnections among conceived entities. Interconnections are cognitive operations that assess the relative positions of entities within the scope of predication. As relational predicates, spatial particles profile a spatial relation on the basis of two other entities in the spatial domain. In the speaker's conceptualization, these two entities trajector and landmark - display an asymmetrical relationship in the same construal event as the relational concept as such.

Spatial particles express the construal of a situation where two entities are conceived as related to each other, and consequently can be regarded as the arguments of that predication. In that construal, the trajector is more salient once perceived and more dynamic than the landmark, which is secondary and more static. The former is the localized or foregrounded entity, and is construed as the movable element in the relationship. On the other hand, the landmark functions as a localizer, background or referential entity, construed as the static element or reference point in the relationship.

In terms of thematic frame, we say that the Logical Structure of spatial particles consists of two roles that are instantiated by the trajector and the landmark of the construal event. The term Logical Structure has been used in formal models of language to refer to verbal argument structure. The arguments of spatial predicates (x, y) designate the roles played by the trajector and the landmark. It is important to notice here that the terms trajector and landmark designate two participants in a construal event configuration, whereas arguments $(\mathrm{x}, \mathrm{y})$ are constructional functions of those participants.

Thus, in the context of the LCM it is realistic to represent the argument structure of spatial relational predicates as a combination of two arguments. In the LCM, therefore, 
LTs of spatial relational predicates include the argument structure (x, y). Let us consider the preposition at as an example:

$$
\text { at }(\mathrm{x}, \mathrm{y}) \text { : The train at the station } \rightarrow \text { at (train, station) }
$$

Spatial relations are, therefore, instantiated in language usage in the form of predications where the spatial predicate takes two arguments instantiated by the construed trajector and landmark, both being necessary for the conceptualization of the relationship expressed.

\section{III.2. Semantic primitive}

The NSM (Wierzbička 1996) provides a set of primitives that we adopt as a departure set in order to define the top of the conceptual hierarchy in the lexical domain of spatial relations. The NSM holds the following distinctions for spatial meaning:

Space

$\rightarrow$ WHERE/PLACE, HERE ABOVE, BELOW, FAR, NEAR, SIDE, INSIDE, TOUCHING

$\begin{array}{lll}\text { Movement } & \rightarrow & \text { MOVE } \\ \text { Intensifiers } & \rightarrow & \text { VERY, MORE }\end{array}$

Some of these terms express typologically-proven primes that can be represented by generic denominations. Thus, WHERE/PLACE can be designated by the term "place”, HERE can be designated by "speaker's location”, ABOVE and BELOW by "higher level than” and “lower level than”, and TOUCHING by “contact”. 2

In the context of LCM formalization, the primitive MOVE can be identified with the expression [BECOME be-LOC’ (y, z)], which expresses the fact that an entity y changes its location with respect to a place $z$. The intensifier VERY can be identified with the Lexical Function MAGN, which expresses intensification. The form “MORE” can be identified with the PLus Lexical Function, which expresses a higher degree in relation to a reference point. In sum, each prime defines a subdomain of the lexical domain of spatial particles, which is represented in the syntactic module of an LT. 


\section{III.3. Lexical hierarchy}

It is not assumed as an initial hypothesis that English has a particular word for each one of the primitives described above. We use the NSM list as our initial set of semantic primitives, i.e., as nuclear terms from which other terms can be defined by means of Lexical Functions.

\section{III.4. Aktionsart distinctions}

Aktionsart distinctions provide a characterization of the trajector/landmark asymmetric construal in terms of situation types (Dik 1997). With regard to this issue, extensive corpora analysis (Navarro 2003, Silvestre 2009) shows that, for some particles, the trajector is conceived as the controller of the spatial relationship (at, on), whereas in other cases it is the Landmark that prototypically controls or constrains the trajector's potential motion (in, under). That evidence leads to the postulation of two possible Aktionsart role configurations, or situation types, of the TR-LM relationship:

a. Position: Positioner (TR) and location (LM)

b. State: Experiencer (TR) and location (LM)

One of these Aktionsart configurations is assigned to a spatial particle LT, depending on which argument of the predication exerts control, according the construal configuration of the situation. Some spatial predicates express a first argument position, in the sense that the entity holds control of the relationship, like at or on, as in examples (3) and (4).

(3) The fly at the piece of melon

(4) The fly on my hand

Other spatial relation predicates express a situation where the first argument undergoes a state of affairs, in the sense that it is the second argument (LM) that controls the spatial relationship and the potential motion of the first argument (TR), as in examples (5) and (6).

(5) The fly in my hand

(6) The fly under the piece of melon 


\section{III.5. Lexical Functions}

Lexical Functions represent world knowledge and specify differences between lexical items in the same domain. World knowledge about space (Clark 1973, Piaget and Inhelder 1956, Talmy 2000, Vygotsky 1986) seems to conform to Merleau Ponty’s (1945) phenomenology of perception, where perception, self-motion and interaction cooccur as a single phenomenon. Figure 1 elaborates on this conception of human experience, by incorporating two subtypes of interaction, as humans accommodate to the environment or modify it so as to assimilate it to their needs.

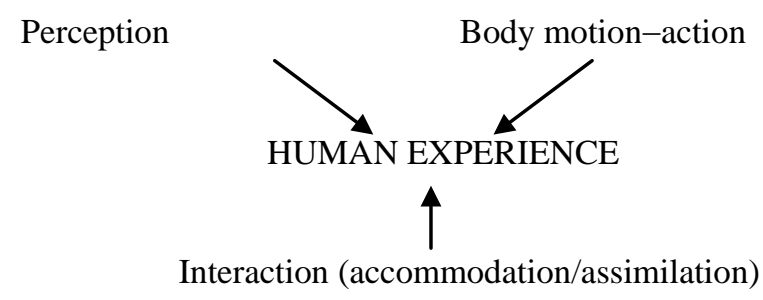

Figure 1. Components of human experience (from Navarro 2006).

In this line, Deane (1993, 2005) proposed the multidimensional character of the semantic structure of spatial relations. According to that view, Navarro (2006) points out that a preposition expresses not only the mere location of the trajector with respect to the landmark, but rather a locative configuration, with a particular orientation for movement, for some kind of purpose. That author's multimodal semantic networks distinguish three aspects of meaning for the construal of spatial relations:

a) Topology: The perception of topological arrangements, determined by human perceptual capacities, which in the case of spatial semantics are mainly visual capacities.

b) Kinetics: Sensory-motor experience about the kinetic action of objects determined by human motor capacities.

c) Function: In order to facilitate survival, assimilation of the environment, as well as accommodation of the body to it, determine our interaction with other people and locations - social and physical interaction.

We assume that every Lexical Function within an LT will correlate with one of these three experiential dimensions, as illustrated in Figure 2. 


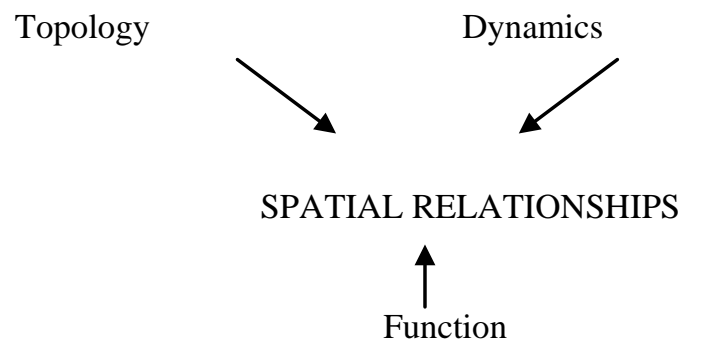

Figure 2. Components of human experience of spatial relationships.

\section{SOME EXAMPLES OF SPATIAL PARTICLE LTS}

In this section we introduce and discuss some LTs of spatial particles. Let us begin with the LT of the preposition at:

At:

[T-MAGN, D-INTENT 1 , F-PURP 1 , F-INSTR 2 ] [position $<(*$ [BECOME be-LOC (x)]) NEAR $>$ ] $(\mathrm{x}, \mathrm{y})$

Semantic decomposition of this lexical unit (Navarro 2002) encompasses the following specifications:

- Argument structure including two arguments $\mathrm{x}$ and $\mathrm{y}$. The former refers to the antecedent of the preposition and the latter to its complement (semantically construed as trajector and landmark, respectively).

- The semantic prime NEAR, expressing the fact that this preposition belongs to a lexical subdomain of relational predicates where the relationship designates proximity between the arguments.

- The expression $(*[$ BECOME be-LOC $(\mathrm{x})]$ ) indicates that this preposition may participate in constructions where motion of argument $\mathrm{x}$ is expressed. The asterisk outside the square brackets and encircled between round brackets indicates that the predicate is compatible with constructions and other lexical items that express change of location, or movement, of the argument $\mathrm{x}$, but this motion is not expressed by this particular predicate on its own.

- The term 'position' shows the situation type or interaction type expressed by this preposition. Particularly, it indicates that the first argument $(\mathrm{x})$ is construed as a positioner in relation to the landmark (y), i.e., that the semantics of this particle implies certain control on the part of the trajector. 
- Lexical Functions in the semantic module specify the semantics of the particle more precisely. Contiguity of trajector and Landmark is indicated by MAGN, which is an intensifier function of the topological aspect (T-) expressed by NEAR (proximity). The function D-INTENT 1 indicates dynamic intentionality of the first argument $(\mathrm{x})$. The function F-PURP $_{1}$ indicates that the first argument is functionally oriented for some purpose. Finally, the function F-INSTR 2 indicates that the second argument is functionally conceived as an instrument or some manipulated entity.

(7) Laura (sat down) at the piano stretching her hands.

In (7) we can observe the prototypical meaning of this preposition as depicted in the LT above. The trajector $\left(\mathrm{x}=\right.$ Laura) takes $\left(\mathrm{D}-\mathrm{INTENT}_{1}\right.$ ) position NEAR and contiguous (MAGN) to the landmark ( $\mathrm{y}=$ the piano), with the purpose (F-PURP ${ }_{1}$ ) of playing it (F$\mathrm{INSTR}_{2}$ ). The verb sat down may express movement or a stative situation. The same expression without any verb expresses a vague stative situation. On the other hand, the same context allows for verbs of movement such as run, rush, etc.

Secondly, we propose the LT of the preposition on in the following terms:

On:

[D-CONT, F-CONTROL ${ }_{1}$, F-INSTR $\left._{2}\right]$ [position $<(*$ BECOME be-LOC (x)] CONTACT $>(\mathrm{x}, \mathrm{y})$

In the case of on, the CONTACT semantic primitive defines the lexical subdomain, which corresponds to TOUCHING in NSM terminology. The situation type is a position, indicating that the trajector $(\mathrm{x})$ controls the spatial relationship with the landmark (y). Again, as in the previous LT, the asterisk indicates that the predicate on is compatible with constructions and lexical items where motion of the argument (x) is expressed, but on does not express this meaning on its own. The lexical function D-CONT expresses a dynamic aspect of continuity. The lexical function F-CONTROL ${ }_{1}$ expresses the idea that the trajector (x) exerts functional control of the situation. Finally, the function F-INSTR 2 expresses the fact that the landmark is instrumentalized. The three functions together constitute the meaning of support, which implies that the trajector uses the landmark to maintain its position, contrarily to previous accounts of the concept "support" that confer a controlling character upon the trajector (Vandeloise 2003).

(8) The cat is on the mat 
In (8) there is CONTACT between the cat (x) and the mat (y). The cat is in a controlled (F-CONTROL ${ }_{1}$ ), continuative (D-CONT) position, where it uses the mat (F-INSTR 2 ). The context allows for verbs of motion such as land, fall, etc.

The LT of the preposition in differs from the previous ones in several respects. In the meaning of this preposition the central role of a control parameter has been pointed out in previous research (Navarro 2000, Vandeloise 1994, 2005).

In:

$[$ F-Control 2$]$ [state $<(*[$ BECOME be-LOC (x)]) $\operatorname{INSIDE~}>(\mathrm{x}, \mathrm{y})]$

The semantic prime INSIDE defines the lexical subdomain, expressing that the trajector (x) bears a spatial relationship with the inner side of the landmark. Motion is not expressed by the predicate itself, though it is compatible with dynamic contexts, as indicated by the asterisk. The situation type is a state where the trajector has no control, or position, but suffers instead, as an experiencer, the consequences of its location. The lexical function F$\mathrm{Control}_{2}$ expresses the idea that the second argument is viewed as a control factor over the trajector. Semantic shifts could result in pragmatically inferred senses such as protection, seclusion or others, which define the extensions of the semantic category.

(9) The present is in the box

In (9) the conceived construal establishes a relationship between the trajector (present) and the inner side of the landmark (box). The relationship implies the limited or controlled mobility of the affected trajector (state), as effected by the landmark (F-Control 2 ).

The particle under presents a compound element in the slot for the nuclear term or primitive: near + below.

Under:

[F-constraint ${ }_{2}$ [ state $<(*$ BECOME be-LOC $\left.(x)]\right)$ NEAR BELOW $\left.>(x, y)\right]$

The LT of the particle "under" incorporates two primitive concepts. On the one hand, NEAR implies a proximity relationship whereas, on the other hand, BELOW indicates that the trajector is located at a lower level than the landmark. The asterisk preceding the expression [BECOME be-LOC (x)] expresses the compatibility of the particle with motion predicates. The situation type "state” signals the trajector's role as the experiencer. The 
Lexical Function [F-constraint ${ }_{2}$ ] shows that the relationship is functionally construed in such a way that the trajector is constrained by the landmark, either physically or otherwise.

(10) The man was caught under the log

In (10) the entity "man" bears a relationship with the entity "log" so that the former is topologically near and below the latter. Functionally, "man” is seen as being in a state of constraint or restricted motion. It could be argued that the primitive "CONTACT" is also an attribute of the concept. However, not all contexts where this particle is used show contact between the participants. The Lexical Function of constraint accounts for a wider range of uses, including all those where CONTACT is also part of the conceptualization.

Next, we briefly discuss the contrast between onto and into versus on and in, respectively.

Onto:

[F-Control 1 , F-Instr 2 ] [position $<$ [BECOME be-LOC (x)] CONTACT $>(\mathrm{x}, \mathrm{y})$

Into:

[F- Control $_{2}$ ] [state $<$ [BECOME be-LOC (x)] $\left.\operatorname{INSIDE~}>(\mathrm{x}, \mathrm{y})\right]$

As we can observe, the LT for these two particles have no asterisk accompanying the expression "[BECOME be-LOC (x)]". Therefore, the motion meaning is intrinsic to these particles, which must lead to the conclusion that no other motion predicates in the same construction are needed in order to express motion. In most other respects, the LTs coincide with on and in, respectively. The only difference between onto and on resides in a lexical function D-CONT that indicates the continuity of contact.

(11a) The dogs ran onto the street

(11b) Let the dogs onto the street

(12a) The dogs ran into the house

(12b) Let the dogs into the house

As we see in (11b) and (12b), the sense of motion is contributed by the particle, and the role of the verb in (11a) and (12a) is reduced to express the manner of motion.

Following CG postulates, semantic properties specified for each parameter in these LTs are prototypical rather than requirements for each lexical unit or predicate. This fact implies that once we have determined the information in each of the components of the LT for a particular lexical unit or predicate, the result would represent the prototypical 
semantics of that predicate, without taking into consideration partial sanction, semantic elaborations, shifts, or metaphorical extensions of that predicate category.

\section{LEXICAL SUBSUMPTION}

The LTs described above show the compatibility of particles with motion constructions. In some cases, the motion meaning is required from other linguistic units (either lexical units or constructions), and in some other cases it is contributed by the particle itself (into, onto). According to the principle of semantic coherence (Goldberg 2006: 40), verb and argument must be semantically compatible. Furthermore, profiled participant roles of the relational lexical items (verbs and particles) must be encoded by profiled argument roles of the construction, with the exception that, if a verb has three profiled roles, one can be represented by an unprofiled argument role, according to the principle of correspondence (Goldberg 2006: 40). The participants that are highly relevant to a verb meaning are likely to be the ones that are relevant or important to a particular linguistic use, since this particular verb was chosen among other alternatives.

In view of these remarks, we expect constructions to match the lexical specifications expressed by the LTs, either of verbs or particles, or both; otherwise the construction must override some of the predicate semantic specifications (Override Principle).

In addition to the general principles stated above, some cases of subsumption may require further constraint principles, as described by Mairal and Ruiz de Mendoza (2009: 188-192) and Peña (2009: 746):

- Full matching: there must be full identification of variables, subevents, and operators between LTs and CTs.

- Event identification condition: correspondence is required between the various subevents (i.e., bundles of operators and variables) into which a lexical and constructional configuration can be segmented.

- Lexical class constraint, i.e., restrictions due to class ascription (e.g. change of state break - versus existence - destroy - in the inchoative construction).

- Lexical blocking: one of the components of the LT can block the fusion with a certain construction given that this component is a suppletive form (e.g. kill, die). 
- Predicate-argument conditioning: co-instantiation of a verbal predicate with one argument places restrictions on the kind of instantiating element that we can have for other constructional arguments.

- Internal variable conditioning: the internal predicate variables place constraints on the nature of both the predicate and constructional arguments.

Apart from these constraints, a process of accommodation or coercion may take place. Coercion is only possible when a construction requires a particular interpretation that is not independently coded by particular LTs. The entire expression is judged grammatical to the extent that the occurring lexical items can be coerced by the construction into having a different but related interpretation to the one specified in their LTs. Therefore, the construction is able to coerce the locative term into a directional reading.

In this line, according to Goldberg, locative terms are coerced by the intransitive and the caused motion constructions into having a directional meaning related to their meaning, and "the location encoded by the locative phrase is interpreted to be the endpoint of a path to that location” (Goldberg 1995: 159). Conversely, our data show that it is not always the construction that coerces the spatial particle into having a directional meaning, but some particles contribute that meaning themselves. Interestingly enough, directional particles occur with much more frequency in motion constructions than nondirectional particles.

In the following section, we show patterns of occurrence of directional and non-directional particles in the constructions under scrutiny, i.e., intransitive motion and caused motion, as depicted above (see section 2).

\section{SPATIAL PARTICLES IN THE INTRANSITIVE MOTION AND THE CAUSED MOTION CONSTRUCTION}

With the purpose of testing the degree of semantic relevance of the spatial particle in the subsumption process, we researched the co-occurrence of eight English prepositions at, in, on, under, behind, over, onto, into - in the intransitive motion construction [do' (x) [BECOME NOT be-LOC' $(\mathrm{x}, \mathrm{z})$ ] and in the caused motion construction [do' (x, y)] CAUSE [BECOME NOT be-LOC' $(y, z)]$. In order to guarantee a fair representation of 
different types of verbs, a prototypical verb was chosen from each one of the Aktionsart types, as distinguished in LCM. The data source used was the Corpus of Contemporary American English (COCA ${ }^{\odot}$ Mark Davies). For each verb-preposition pair, 200 instances of Intransitive Motion or Caused Motion expressions were analysed in context. The data obtained show evidence in the following directions, as summarized in Tables I and II:

1. Stative verbs do not occur in motion constructions. However, certain spatial particles, like onto and into license causative stative verbs (e.g. scare) into the caused motion construction.

(13) ..., to scare the kid onto the sidewalk.

(14) I think someone scared him into hiding.

2. All particles co-occur with active accomplishment verbs (e.g. come, get, put) in both constructions.

3. Only over and into co-occur with achievement verbs (e.g. shatter), in motion constructions in our sample.

(15) Glass shatters loudly all over the sink

(16) ... it isn't the candy that has shattered into rocky rubble, but my back molar

(17) Crane shatters the glass bottle over the table

(18) ... rocket-propelled grenades shattered the column into a hysterical mob

4. Semelfactives (e.g. sneeze, glimpse) do not occur in motion constructions. Though into does occur in some intransitive expressions, the construction does not imply change of location of argument $(\mathrm{x})$.

(19) Teach your child to cough or sneeze into his elbow

5. All particles except on co-occur with activity verbs in both constructions. Though on co-occurs with activity verbs (e.g. run), it does not, however, express the end of a path, but a location where the activity takes place.

(20) ... a set of vines had started to run on the wall

(21) The woman ran her hand on the sill

6. Onto, into and over co-occur with accomplishments (e.g. melt) in intransitive motion constructions. In the caused motion construction, in is also used. 
Table 1. Spatial particles and Aktionsart classes in the Intransitive Motion Construction. ${ }^{3}$

\begin{tabular}{|c|c|c|c|c|c|c|}
\hline $\begin{array}{l}\text { verb } \\
\text { Aktionsart }\end{array}$ & $\begin{array}{l}\text { state } \\
\text { know }\end{array}$ & $\begin{array}{l}\text { activity } \\
\text { run }\end{array}$ & $\begin{array}{l}\text { achievement } \\
\text { shatter }\end{array}$ & $\begin{array}{l}\text { semelfactive } \\
\text { sneeze } \\
\text { /glimpse }\end{array}$ & $\begin{array}{l}\text { accomplishment } \\
\text { melt }\end{array}$ & $\begin{array}{l}\text { active } \\
\text { accomplishment } \\
\text { come / get }\end{array}$ \\
\hline \multicolumn{7}{|l|}{ Particle } \\
\hline at & no & yes & no & no/ no & no & YES / YES \\
\hline under & no & yes & no & no / no & no & YES / YES \\
\hline on & no & $?$ & no & no / no & $?$ & YES / YES \\
\hline behind & no & yes & no & no /? & no & YES / YES \\
\hline in & no & yes & $?$ & no / no & no & YES / YES \\
\hline onto & no & yes & no & no / no & yes & YES / YES \\
\hline over & no & YES & yes & no / no & yes & YES / YES \\
\hline into & no & YES & YES & $? / ?$ & YES & YES / YES \\
\hline
\end{tabular}

Table 2. Spatial particles and Aktionsart classes in the Caused Motion Construction.

\begin{tabular}{|c|c|c|c|c|c|c|}
\hline $\begin{array}{l}\text { verb } \\
\text { Aktionsart } \\
\text { class }\end{array}$ & $\begin{array}{l}\text { causative } \\
\text { stative } \\
\text { scare }\end{array}$ & $\begin{array}{l}\text { causative } \\
\text { activity } \\
\text { run }\end{array}$ & $\begin{array}{l}\text { causative } \\
\text { achievement } \\
\text { shatter }\end{array}$ & $\begin{array}{l}\text { causative } \\
\text { semelfactive } \\
\text { sneeze / } \\
\text { glimpse }\end{array}$ & $\begin{array}{l}\text { causative } \\
\text { accomplishment } \\
\text { melt }\end{array}$ & $\begin{array}{l}\text { causative } \\
\text { active acc. } \\
\text { put }\end{array}$ \\
\hline \multicolumn{7}{|l|}{ Particle } \\
\hline at & no & yes? & no & no / no & no & YES \\
\hline under & ? & yes & no & no / no & no & YES \\
\hline on & no & ? & no & no / no & $?$ & YES \\
\hline behind & no & yes & no & no / no & no & YES \\
\hline in & $?$ & yes? & no & no / no & yes? & YES \\
\hline onto & yes? & yes & no & no /no & yes & YES \\
\hline over & no & YES & yes & no / no & yes & YES \\
\hline into & YES & YES & YES & ? / ? & yes & YES \\
\hline
\end{tabular}

\section{DISCUSSION}

In light of the results shown above, we may suggest some hypotheses about the semantic contribution of some particles in motion constructions.

The spatial particles into, over and onto contribute the semantic prime MOVE or [BECOME be-LOC (x)], that is, they express a trajector's change of location. This fact is reflected in the LTs of these particles and has also been proven by the examples in our 
sample. As a consequence, these particles make it possible for the intransitive motion construction to license non-dynamic verbs (achievements and accomplishments), because these are telic. On the other hand, into, over and onto make it possible for the caused motion construction to license causative verbs, even if these do not contribute the semantics of motion, or 'change of location' (causative stative, causative achievement, causative accomplishment).

On the other hand, achievements (shatter) and accomplishments (melt), or their causative uses, do not occur in motion constructions with other particles that do not contribute the motion sense. In these cases, no lexical item contributes the 'change of location' sense, and neither does the construction. The construction alone cannot coerce a lexical item into subsumption. Conversely, it is the spatial particle (into, onto, over) or the lexical verb (put, come, get) that contributes the 'change of location' sense. Thus, if we find a spatial particle like at, on or under following a non-telic verb like shatter or melt, the intransitive motion construction, or the caused motion construction, cannot occur, as can be seen in examples (22) and (23):

(22) In the oven, melt cheese on the croutes

(23) The ice melted under the lamp

Nor can causative stative verbs occur in caused motion constructions if no 'change of location' sense is brought in by the spatial particle, as we see in the contrast between (24) and (13), reproduced here as (25):

(24) don't scare people at the mall

(25) ..., to scare the kid onto the sidewalk

Activity verbs (run), active accomplishment verbs (come, get), and their causative correspondents (run, put) license most of the spatial particles into both the intransitive motion construction and the caused motion construction. These verb types are those that express durative dynamic events. In these cases, verb semantics contributes the agentive character of the mover or causer. Thus, activity verbs can usually occur in motion constructions with most particles. However, the pairs in vs. into and on vs. onto do not behave likewise in co-occurrence with activity verbs. Whereas into and onto occur normally in motion constructions with activity verbs, as it is to be expected from their own semantics, in and on only occur with activity verbs in motion constructions where 
'change of location' is ambiguous, or ambiguity results between motion and locative constructions, as illustrated in the following examples - (20) and (21) as (26a) and (27a):

(26a) ... a set of vines had started to run on the wall

(26b) ... a set of vines had started to run onto the wall

(27a) The woman ran her hand on the sill

(27b) The woman ran her hand onto the sill

(28a) We saw people run in (and out of) the house

(28b) We saw people run into (and out of) the house

(29a) photographs of them were run in all the newspapers

(29b) photographs of them were run into all the newspapers

In view of these facts, we may suggest that spatial particles might be considered lexical entries that contribute some semantic content to the constructions they occur in, rather than just mere formal devices marking a locative argument.

\section{FINAL REMARKS}

The proposal presented here for a formalization of spatial particle LTs is rather tentative, given that no universal semantic meta-language has yet been established for topological, dynamic and functional spatial configurations. Further research points at the consolidation of a meta-language that expresses Lexical Functions of spatial particles in diverse languages.

The relevance of semantic descriptions of spatial particles may turn out to be more important than has been considered to date in cognitive functional models.

A further step is the investigation of subsumption constraints of spatial particle predicates in different constructions, since constructions like the Caused Motion Construction do not license all verbs. We could start by checking which spatial particles occur and which ones do not occur in the Caused Motion Construction, for instance, and then see whether a particular preposition licenses the use of certain verbs in the construction. For example, preliminary observations through corpus analyses suggest 
that into and onto license some stative verbs in the Caused Motion Construction (e.g. she scared him into a depression).

Since spatial particles contribute meaning and are relational predicates (like verbs), we could account for some constructions as encompassing two predications, one as the main predication and the other as a secondary one. Each predication can be described in terms of argument structure. According to our view, spatial particles are predicates that relate two arguments, trajector and landmark, which may be shared by other relational predicates occurring in the same construction.

Finally, the metaphorical and figurative uses of spatial particles could also be studied as instantiations of external constraints in LCM.

\section{Notes}

${ }^{1}$ Financial support for this research has been provided by the Fundació Bancaixa Castelló - Universitat Jaume I, grant P1 1A2010-14 and the Spanish Ministerio de Ciencia e Innovación, grant FFI2010-17610.

$\stackrel{2}{2}$ This is a terminological issue that we do not tackle here due to lack of space.

$\underline{3}$ For a proper understanding of Table 1 and Table 2, the reader should take into account the following specifications:

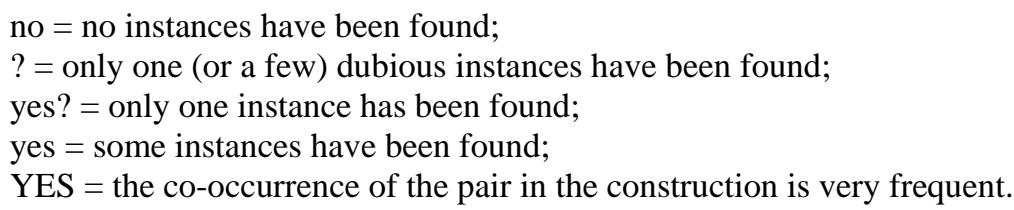

\section{REFERENCES}

Butler, Ch.S. 2009. “The Lexical Constructional Model. Genesis, strengths and challenges”. In Butler Ch.S. and J. Martín Arista, (Eds.) Deconstructing Constructions. Amsterdam: John Benjamins, 117-151.

Clark, H.H. 1973. "Space, time, semantics and the child”. In Moore, T.E. (Ed.) Cognitive Development and the Acquisition of Language. London: Academic Press, 27-64.

Davies, M. (C) COCA. Corpus of Contemporary American English. $<\underline{\text { http://corpus.byu.edu/coca/ }>}$ 
Deane, P.D. 1993. “At, by, to, and past: An Essay in Multimodal Image Theory”. BLS, 19, 112-124.

Deane, P.D. 2005. “Multimodal spatial representation: On the semantic unity of over”. In Hampe, B. (Ed.) From Perception to Meaning. Image Schemas in Cognitive Linguistics. Berlin: Mouton de Gruyter, 235-284.

Dik, S.C. 1997. The Theory of Functional Grammar: The Structure of the Clause. Berlin: Mouton de Gruyter.

Faber, P. and Mairal, R. 1999. Constructing a Lexicon of English Verbs. Berlin: Mouton de Gruyter.

Goldberg, A.E. 1995. Constructions. A Construction Grammar Approach to Argument Structure. Chicago: The University of Chicago Press.

Goldberg, A.E. 2006. Constructions at Work. The Nature of Generalizations in Language. Oxford, UK: Oxford University Press.

Langacker, R.W. 1987. Foundations of Cognitive Grammar. Volume I, Theoretical Prerequisites. Stanford CA: Stanford University Press.

Langacker, R.W. 2008. Cognitive Grammar. An Introduction. Oxford, UK: Oxford University Press.

Mairal, R. 2004. "Reconsidering lexical representations in Role and Reference Grammar”. Proceedings of XXVII International AEDEAN Conference. Universidad de Salamanca.

Mairal, R. and Faber, P. 2005. "Decomposing semantic decomposition”. Proceedings of the 2005 International Conference on Role and Reference Grammar, Taiwan: Academia Sinica, 279-308.

Mairal, R. and Faber, P. 2007. "Lexical templates within a functional cognitive theory of meaning”. Annual Review of Cognitive Linguistics, 5, 137-172.

Mairal, R. and Ruiz de Mendoza, F.J. 2008. "New challenges for lexical representation within the Lexical-Constructional Model”. Revista Canaria de Estudios Ingleses, 57, 137-158. 
Mairal, R. and Ruiz de Mendoza, F. J. 2009. "Levels of description and explanation in meaning construction”. In Butler, Ch.S. and J. Martín Arista (Eds.) Deconstructing Constructions. Amsterdam/Philadelphia: John Benjamins, 153 - 198.

Mel'čuk, I., Clas, A. and Polguère, A. 1995. Introduction à la Lexicologie Explicative et Combinatoire. Louvain-la-Neuve (BE) and Aupelf: Duculot-UREF.

Merleau-Ponty, M. 1945. Phénoménologie de la Perception. Paris: Gallimard.

Navarro, I. 2000. “A Cognitive-Semantic Analysis of the English Lexical Unit in”. Cuadernos de Investigación Filológica, 26, 189-220.

Navarro, I. 2002. “Towards a description of the semantics of AT”. In Cuyckens, H. and G. Radden (Eds.) Perspectives on Prepositions. Tübingen: Niemeyer, 210-230.

Navarro, I. 2003. A Cognitive Semantics Analysis of the English Lexical Units At, On, and In in English. CESCA. < http://www.tdx.cesca.es/TDX-0804103-133233/>

Navarro, I. 2006. "Functional contrasts in spatial meaning”. Studia Universitatis Petru Maior. Series Philologia, 5, 133-144.

Peña, S. 2009. "Constraints on subsumption in the caused-motion construction". Language Sciences, 31, 740-765.

Pérez-Hernández, L. and Peña-Cervel, S. 2009. "Pragmatic and Cognitive Constraints on Lexical-Constructional Subsumption”. Atlantis, 31 (2), 57-73.

Piaget, J. and Inhelder, B. 1956. The Child's Conception of Space. London: Routledge and Kegan Paul.

Ruiz de Mendoza, F.J. and Mairal, R. 2007a. "Challenging systems of lexical representation”. Journal of English Studies, 6, 325-356.

Ruiz de Mendoza, F.J. and Mairal, R. 2007b. "Levels of semantic representation: Where lexicon and grammar meet”. Interlingüística, 17, 26-47.

Ruiz de Mendoza, F.J. and Mairal, R. 2008. "Levels of description and constraining factors in meaning construction: An introduction to the Lexical Constructional Model”. Folia Linguistica, 42 (2), 355-400.

Silvestre, A.J. 2009. "Topology, force-dynamics, and function in the semantics of In and $\mathrm{On}$ as the prepositional component of English prepositional verbs”. In 
Valenzuela, J., A. Rojo and C. Soriano (Eds.) Trends in Cognitive Linguistics: Theoretical and Applied Models. Frankfurt am Main: Peter Lang, 51-64.

Talmy, L. 2000. “How language structures space”. In Talmy, L. Toward a Cognitive Semantics. Cambridge, MA: MIT Press, 177-254.

Vandeloise, C. 1994. "Methodology and analyses of the preposition in". Cognitive Linguistics, 5 (2), 157-184.

Vandeloise, C. 2003. “Containment, support, and linguistic relativity”. In Cuyckens, H., R. Dirven and J.R. Taylor (Eds.) Cognitive Approaches to Lexical Semantics. Berlin: Mouton de Gruyter, 393-426.

Vandeloise, C. 2005. "Force and function in the acquisition of the preposition in". In Carson, L. and E. van der Zee (Eds.) Functional Features in Language and Space. Oxford: Oxford University Press, 219-231.

Van Valin, R.D. Jr. 2005. The Syntax-Semantics-Pragmatics Interface: An Introduction to Role and Reference Grammar. Cambridge, UK: Cambridge University Press.

Vendler, Z. 1967. Linguistics in Philosophy. Ithaca and London: Cornell University Press. Vygotsky, L.S. 1986. (1st ed. 1934). Thought and Language. Cambridge, MA: MIT Press. Wierzbička, A. 1996. Semantics: Primes and Universals. Oxford, UK: Oxford University Press.

Received October 2011

Cite this article as:

Navarro, I. 2011. "Lexical decomposition of English spatial particles and their subsumption in motion constructions”. Language Value, 3 (1), 114-137. Jaume I University ePress: Castelló, Spain. http://www.e-revistes.uji.es/languagevalue.

ISSN 1989-7103

Articles are copyrighted by their respective authors 